\title{
The C-terminal domain of the Salmonella enterica WbaP (UDP-galactose:Und-P galactose-1-phosphate transferase) is sufficient for catalytic activity and specificity for undecaprenyl monophosphate
}

\author{
Kinnari B Patel ${ }^{2}$, Ewa Ciepichal ${ }^{4}$, Ewa Swiezewska ${ }^{4}$, \\ and Miguel A Valvano ${ }^{1,2,3}$

\begin{abstract}
${ }^{2}$ Department of Microbiology and Immunology, Center for Human Immunology and ${ }^{3}$ Department of Medicine, University of Western Ontario, London, ON, Canada N6A 5C1; and ${ }^{4}$ Institute of Biochemistry and

Received on July 2, 2011; revised on July 2, 2011; accepted on August 10,
\end{abstract} \\ Biophysics, Polish Academy of Sciences, Pawinskiego 5a, 02-106 Warsaw, \\ Poland \\ 2011
}

Two families of membrane enzymes catalyze the initiation of the synthesis of $\mathbf{O}$-antigen lipopolysaccharide. The Salmonella enterica Typhimurium WbaP is a prototypic member of one of these families. We report here the purification and biochemical characterization of the WbaP C-terminal $\left(\mathrm{WbaP}_{\mathrm{CT}}\right)$ domain harboring one putative transmembrane helix and a large cytoplasmic tail. An Nterminal thioredoxin fusion greatly improved solubility and stability of $\mathrm{WbaP}_{\mathrm{CT}}$ allowing us to obtain highly purified protein. We demonstrate that $\mathrm{WbaP}_{\mathrm{CT}}$ is sufficient to catalyze the in vitro transfer of galactose (Gal)-1-phosphate from uridine monophosphate (UDP)-Gal to the lipid carrier undecaprenyl monophosphate (Und-P). We optimized the in vitro assay to determine steady-state kinetic parameters with the substrates UDP-Gal and Und-P. Using various purified polyisoprenyl phosphates of increasing length and variable saturation of the isoprene units, we also demonstrate that the purified enzyme functions highly efficiently with Und-P, suggesting that the $\mathrm{WbaP}_{\mathrm{CT}}$ domain contains all the essential motifs to catalyze the synthesis of the Und-P-P-Gal molecule that primes the biosynthesis of bacterial surface glycans.

Keywords: isoprenoid / lipopolysaccharide / membrane protein / O-antigen / sugar transferase

\section{Introduction}

The membrane enzyme WbaP of Salmonella enterica serovar Typhimurium initiates $\mathrm{O}$-antigen synthesis by catalyzing the transfer of galactose (Gal)-1-phosphate from a nucleotide

\footnotetext{
${ }^{1}$ To whom correspondence should be addressed: Tel: +1-519-661-3427; Fax: +1-519-661-3499; e-mail: mvalvano@uwo.ca
}

precursor [uridine monophosphate (UDP)-Gal], onto the membrane-embedded isoprenoid lipid carrier, undecaprenyl monophosphate (Und-P), yielding Und-P-P-Gal (Wang and Reeves 1994; Wang et al. 1996; Patel et al. 2010). WbaP belongs to the polyisoprenyl-phosphate hexose-1-phosphate transferase (PHPT) family (Valvano 2003; Valvano et al. 2011). PHPT members occur only in prokaryotes and initiate the synthesis of various types of glycans such as, for example, colanic acid in Escherichia coli K-12 (Stevenson et al. 1996), K30 capsule in E. coli 09:K30 (Drummelsmith and Whitfield 1999), type 2 capsule in Streptococcus pneumoniae (Cartee et al. 2005) and glycans for S-layer protein glycosylation in Geobacillus stearothermophilus (Steiner et al. 2007). Most proteins in this family utilize hexose sugars, but some exceptions exist: PglC in Campylobacter jejuni and $\mathrm{PglB}$ in Neisseria sp. transfer 2,4-diacetamido-2,4,6-trideoxyglucose (bacillosamine)-1-P and a 2(4)-acetamido-4(2)-glyceramido2,4,6-trideoxyhexose-1-P, respectively, to initiate the synthesis of precursors for protein glycosylation pathways (Power et al. 2000; Glover et al. 2006; Chamot-Rooke et al. 2007; Hartley et al. 2011). Another member of this family, WecP, functions with UDP- $N$-acetylgalactosamine (Merino et al. 2011).

WbaP has five predicted transmembrane (TM) helices and three domains (Saldías et al. 2008; Figure 1). The N-terminal domain, including the first four TMs and their connecting loops, has no assigned function, although it contributes to the overall stability of the protein in the membrane (Saldías et al. 2008). A large predicted soluble loop between TMIV and TMV has been implicated in modulating chain length distribution of $\mathrm{O}$-antigen, while the $\mathrm{C}$-terminal domain that includes TMV and the tail is sufficient for the activity of the enzyme in vivo and in vitro (Wang et al. 1996; Saldías et al. 2008; Patel et al. 2010). Trypsin cleavage and greenfluorescent protein reporter experiments confirmed that the C-terminus of the protein including approximately the last 20 $\mathrm{kDa}$ is cytoplasmic (Patel et al. 2010). Most PHPT proteins studied are predicted to contain five complete TMs, but others such as Caulobacter crescentus PssY and PssZ contain only the C-terminal domain (Toh et al. 2008). At least some of the highly conserved residues within the cytosolic C-terminal region of $\mathrm{WbaP}$ are required for function (Patel et al. 2010). The location of the catalytic domain to a defined region of the protein prompted us to purify and biochemically characterize 


\section{Periplasm}

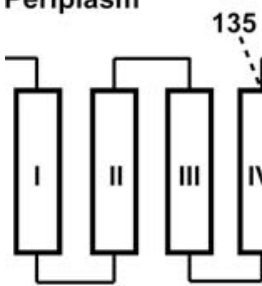

Cytoplasm

Fig. 1. Predicted topology of $S$. enterica WbaP adapted from Saldías et al. (2008).

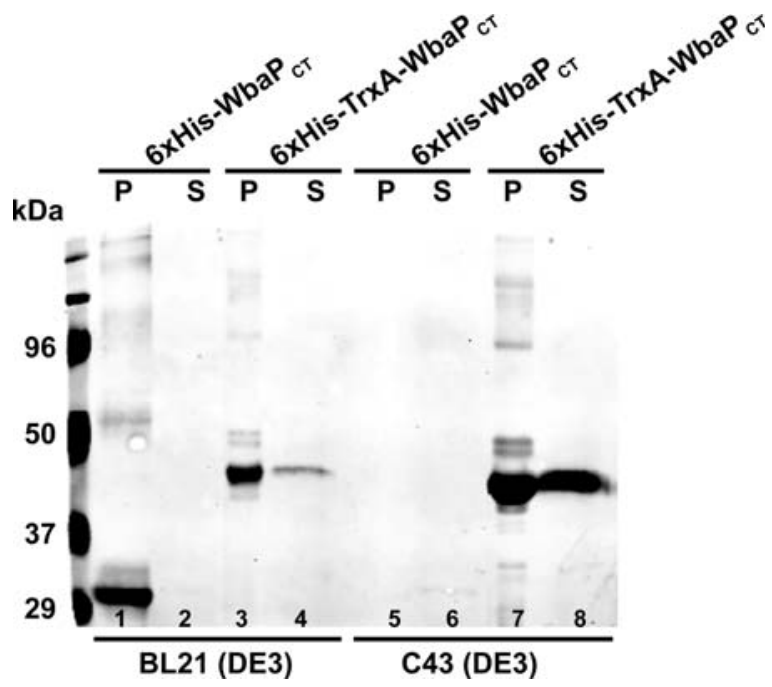

Fig. 2. Solubilization of $6 x$ His- $-\mathrm{WbaP}_{\mathrm{CT}}$ and $6 \mathrm{xHis}-\mathrm{Tr} \mathrm{AA}-\mathrm{WbaP} \mathrm{P}_{\mathrm{CT}}$ from total membranes of BL21(DE3) and C43(DE3) cells (lanes 1-4 and 5-8, respectively). After IPTG induction and solubilization with $2.5 \% \mathrm{DDM}$, the insoluble pellet $(\mathrm{P})$ and soluble supernatant $(\mathrm{S})$ fractions were recovered as described in Materials and methods. Samples were separated by $14 \%$ SDSPAGE and probed with anti-His antibodies. kDa, molecular mass markers.

the C-terminal domain of WbaP (spanning residues 258-476, $\mathrm{WbaP}_{\mathrm{CT}}$ ) in the absence of contaminating membrane proteins or lipids. Using an in vitro assay with chemically defined components, we demonstrate that $\mathrm{WbaP}_{\mathrm{CT}}$ is sufficient for enzymatic activity and also carries high specificity for the Und-P lipid acceptor.

\section{Results and discussion}

Overproduction and solubilization of the C-terminal domain of WbaP with an $N$-terminal thioredoxin fusion

Salmonella enterica Typhimurium wbaP $P_{\mathrm{R} 274-\mathrm{Y} 476}$ was amplified from LT2 DNA and cloned into pET28a generating the plasmid pKP18. This construct encoded a product with an N-terminal $6 \mathrm{xHis}$ tag to facilitate detection by immunoblot and protein purification by $\mathrm{Ni}^{2+}$-affinity chromatography. Expression of the recombinant protein was under the control of the Isopropyl $\beta-D-$ 1-thiogalactopyranoside (IPTG)-inducible lacZ promoter. After induction of BL21(DE3)/pKP18 with IPTG, total membranes were prepared and analyzed by sodium dodecyl sulfate-polyacrylamide gel electrophoresis (SDS-PAGE). Immunoblotting

revealed a $29-\mathrm{kDa}$ band corresponding to $6 \mathrm{xHisWbaP}_{\mathrm{CT}}$ (data not shown). We next attempted to solubilize $6 x$ His-WbaP ${ }_{C T}$ from the total membrane fractions for purification. To retain the activity of the protein, we tested non-ionic detergents, like Triton $\mathrm{X}-100$ and $n$-dodecyl- $\beta$-D-maltoside (DDM), and the zwitterionic detergent, 3-[(3-cholamidopropyl)dimethylammonio]-1propanesulfonate (CHAPS) at over $10 \times$ their critical micelle concentrations. None of the detergents were successful in extracting $6 \mathrm{xHis}-\mathrm{WbaP}_{\mathrm{CT}}$ from the membrane fractions (data not shown). Varying growth and induction conditions, such as temperature, time, IPTG concentration and aeration, did not improve solubilization, suggesting that BL21(DE3) could produce $6 \mathrm{xHisWbaP}_{\mathrm{CT}}$ as inclusion bodies. Inclusion bodies are typically described for proteins that accumulate in the periplasm or in the cytosol, but can also be membrane associated and therefore detected in the total membrane fraction (Geertsma et al. 2008). An N-terminal fusion of the $12 \mathrm{kDa}$ thioredoxin (TrxA) to a target protein prevents the formation of inclusion bodies (LaVallie et al. 1993). Indeed, we reported previously that an N-terminal TrxA fusion enhanced membrane localization and folding of $\mathrm{WbaP}_{\mathrm{CT}}$ (Patel et al. 2010). We reasoned that if this fusion reduced the production of inclusion bodies, it would improve solubilization by detergents. Plasmid pKP41 expresses $w b a P_{\mathrm{R} 258-\mathrm{Y} 476}$ with an N-terminal 6xHis tag and TrxA fusion (Patel et al. 2010). We solubilized total membranes from BL21(DE3) cells expressing 6xHis-TrxA-WbaP $\mathrm{CT}_{\mathrm{C}}$ and the insoluble $6 \mathrm{xHis}-\mathrm{WbaP}_{\mathrm{CT}}$ in $2.5 \%$ DDM. As before, $6 \mathrm{xHis}-\mathrm{WbaP}_{\mathrm{CT}}$ was not solubilized from total membranes (Figure 2, lanes 1 and 2). In contrast, 6xHis-TrxA-WbaP ${ }_{\mathrm{CT}}$ was well expressed and readily soluble in the detergent suspension (Figure 2, lanes 3 and 4). To improve the solubilization, we repeated the experiments using the C43(DE3) strain. This strain derives from BL21(DE3) and allows for improved expression of membrane proteins (Miroux and Walker 1996). Expression and solubilization of $6 x$ His-TrxA-WbaP ${ }_{\mathrm{CT}}$ was more efficient in C43(DE3) bacteria (Figure 2, lanes 7 and 8), whereas $6 \mathrm{xHis}-$

WbaPCT was not well expressed in these cells (Figure 2, lanes 5 and 6). Similar results were obtained using 6\% CHAPS and 7\% Triton X-100 (data not shown).

To find an efficient detergent for solubilization of 6xHis-TrxA-WbaP $\mathrm{CT}_{\mathrm{T}}$ and compatibility with enzymatic activity, we also tested the non-ionic detergent octylglucoside (OG) at 0.5 and $1 \%$ concentrations. After solubilization and high-speed centrifugation, $2.5 \%$ of the insoluble pellet and the soluble supernatant fractions were analyzed by SDSPAGE and western blotting and the soluble fractions were also tested for enzymatic activity with $20 \mathrm{mM} \mathrm{MgCl}_{2}, 100$ $\mu \mathrm{M}$ Und-P and $0.33 \mu \mathrm{M}{ }^{14} \mathrm{C}$-labeled UDP-Gal. Although DDM was most effective at solubilizing $6 \times \mathrm{xHis}^{-T r x A-W b a P} \mathrm{CT}_{\mathrm{C}}$ (Figure 3), the protein was most active in CHAPS at a concentration of $1 \%$ (Table I). We concluded that DDM was preferred to solubilize and purify $6 \times$ His-TrxA-WbaP ${ }_{C T}$ while CHAPS would be optimal to assay the protein in vitro.

\section{Purification of an active 6xHis-TrxA-WbaP ${ }_{C T}$ protein and} cleavage of the 6xHis fusion partner

6xHis-TrxA-WbaP $\mathrm{CT}_{\mathrm{T}}$ was purified as described in Materials and methods. Total membranes from a $150 \mathrm{~mL}$ culture of $\mathrm{C} 43$ 


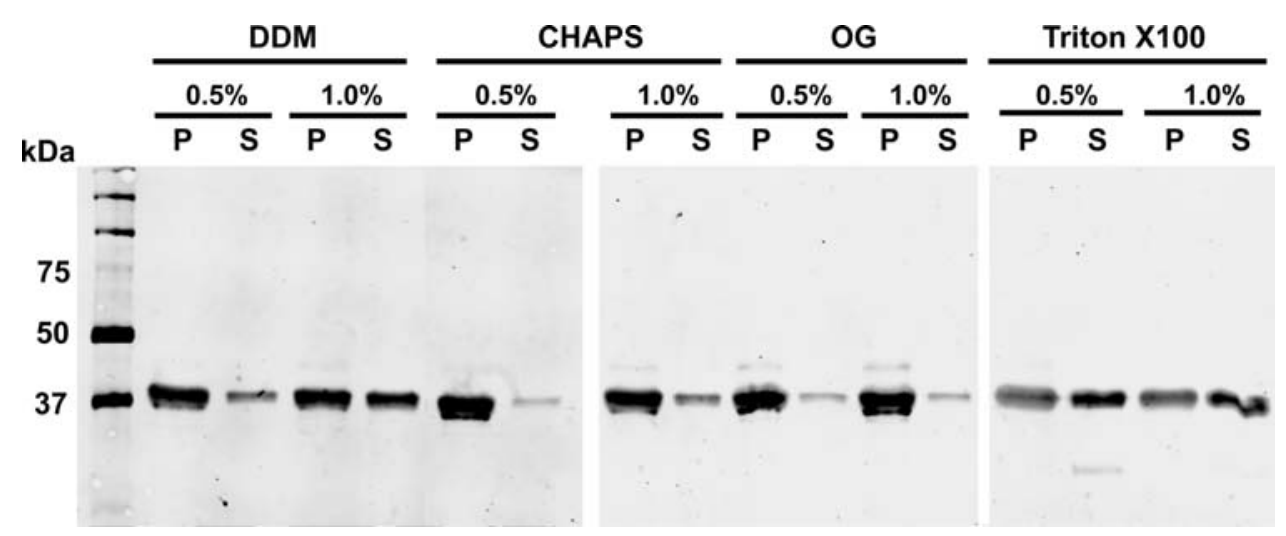

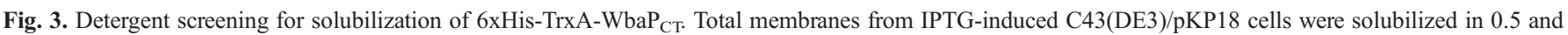

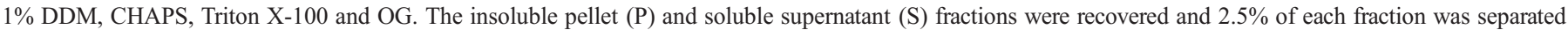
by $14 \%$ SDS-PAGE and probed with anti-His antibodies.

Table I. In vitro activity of $6 x H i s-T r x A-W^{2} P_{C T}$ solubilized with non-ionic detergents

\begin{tabular}{ll}
\hline Sample & $\begin{array}{l}\text { Activity relative to total enzymatic } \\
\text { activity in crude membranes }(\%)^{\mathrm{a}}\end{array}$ \\
\hline Crude membranes with no detergent $^{\mathrm{b}}$ & 100.0 \\
Membrane solubilized (detergent; \%) & \\
CHAPS (0.5) & 62.4 \\
CHAPS (1.0) & 91.8 \\
DDM $(0.5)$ & 81.5 \\
DDM (1.0) & 44.5 \\
OG (0.5) & 65.5 \\
OG (1.0) & 76.5 \\
Triton X-100 (0.5) & 10.0 \\
Triton X-100 (1.0) & 3.5 \\
\hline
\end{tabular}

aTotal membrane protein $(200 \mu \mathrm{g})$ was solubilized in buffer with detergents to a final volume of $200 \mu \mathrm{L} ; 50 \mu \mathrm{L}$ of the soluble fraction corresponding to 50 $\mu \mathrm{g}$ of solubilized membrane protein was tested for in vitro enzymatic activity as described in Materials and methods.

${ }^{\mathrm{b}} 50 \mu \mathrm{g}$ of crude membranes were tested for in vitro enzymatic activity.

(DE3)/pKP41 were solubilized in buffer containing 1\% DDM. Following high-speed centrifugation, the supernatant was recovered and applied to $\mathrm{Ni}_{2}^{+}$-loaded resin. After washing the resin, 6xHis-TrxA-WbaP ${ }_{\mathrm{CT}}$ was eluted with $250 \mu \mathrm{M}$ imidazole. SDS-PAGE and Coomassie staining showed that 6xHis-TrxA-WbaP ${ }_{\mathrm{CT}}$ efficiently bound to the column and was eluted at high levels of imidazole (Figure 4A). After overnight dialysis, the protein concentration was quantified and the purified enzyme remained active as assayed with exogenous Und-P and ${ }^{14} \mathrm{C}$-labeled UDP-Gal (data not shown).

We next proceeded to remove the 6xHis-TrxA fusion by cleavage at the tobacco etch virus (TEV) site between $\mathrm{WbaP}_{\mathrm{CT}}$ and the fusion partner. Pure 6xHis-TrxA-WbaP was incubated with $6 \mathrm{xHis}-\mathrm{TEV}$ overnight at $4^{\circ} \mathrm{C}$. After proteolysis, the sample was added to $\mathrm{Ni}^{2+}$-charged resin and the flow-through and all fractions were analyzed by SDS-PAGE. The TEV cleavage was complete (Figure 4B, lane 3 ) affording $10 \% \mathrm{WbaP}_{\mathrm{CT}}$, whereas the reminder of the cleaved protein remained associated with the resin (Figure 4B, lane 4). The protein recovered in the flow-through was concentrated and quantified (Figure 4C). This protocol provided $0.2 \mathrm{mg} / \mathrm{l}$ of highly purified and enzymatically active $\mathrm{WbaP}_{\mathrm{CT}}$, which was sufficient for the biochemical analysis.

\section{Biochemical properties and kinetic parameters of purified WbaP $_{C T}$}

We measured the effect of different variables in the in vitro transferase activity of $\mathrm{WbaP}_{\mathrm{CT}}$. The optimal $\mathrm{pH}$ was determined using fresh tris- $\mathrm{HCl}$ buffers ranging from $\mathrm{pH} 6$ to 9.5. Transferase activity was only detected between $\mathrm{pH} 7$ and 9, being optimal at $\mathrm{pH} 8.5$ (Figure 5A). Tris- $\mathrm{HCl}$ buffer at $\mathrm{pH} 8.5$ was therefore used for all subsequent reactions. $\mathrm{NaCl}$ and $\mathrm{KCl}$ inhibited $\mathrm{WbaP}_{\mathrm{CT}}$ activity, particularly at concentrations higher than $200 \mathrm{mM}$ salt that resulted in more than 50\% inhibition (Figure 5B). Therefore, upon cleavage of the $6 \times$ His-TrxA, WbaP $_{\mathrm{CT}}$ was concentrated by a filtration spin column and rinsed twice with salt-free buffer to prevent the inhibitory effects of $\mathrm{NaCl}$. In vitro assays with crude membranes containing $\mathrm{WbaP}$ have previously shown that divalent cations $\mathrm{Mg}^{2+}$ or $\mathrm{Mn}^{2+}$ are required for activity (Osborn et al. 1962; Patel et al. 2010). To determine the optimal concentration of metal ion cofactor required for the activity of $\mathrm{WbaP}_{\mathrm{CT}}$, we assayed the protein at concentrations of $0-150 \mathrm{mM} \mathrm{MgCl}_{2}$. Without adding $\mathrm{MgCl}_{2}$, no activity could be detected; activity was optimal at $25 \mathrm{mM}$, while higher concentrations had an inhibitory effect (Figure 5C).

We next investigated the kinetic parameters of $\mathrm{WbaP}_{\mathrm{CT}}$. Product formation was assayed over time at various concentrations of protein. The transferase activity profile was linear up to $15 \mathrm{~min}$ for concentrations of protein up to 4 $\mathrm{ng} / \mu \mathrm{L}$. To determine the steady-state kinetics of $\mathrm{WbaP}_{\mathrm{CT}}$, we utilized optimized reaction conditions $[50 \mathrm{mM}$ tris- $\mathrm{HCl}$ ( $\mathrm{pH} 8.5$ ), $25 \mathrm{mM} \mathrm{MgCl}, 1 \%$ CHAPS] and tested the substrates UDP-Gal and Und-P at concentrations ranging from 0.2 to $2.5 \mu \mathrm{M}$ and 10 to $1000 \mu \mathrm{M}$, respectively. Typical Michaelis-Menten kinetics were observed for both substrates (Figure 6A and B) with a $K_{m}$ of $0.55 \pm 0.06 \mu \mathrm{M}$, a $V_{\max }$ of $2448 \pm 93 \mathrm{pmol} / \mathrm{mg} / \mathrm{min}$ and $k_{\text {cat }}$ of $4.025 \mathrm{~s}^{-1}$ for UDP-Gal, and a $K_{m}$ of $78.5 \pm 0.02 \mu \mathrm{M}$ and a $V_{\max }$ of $1145 \pm 65 \mathrm{pmol} / \mathrm{mg} / \mathrm{min}$ for Und-P. 

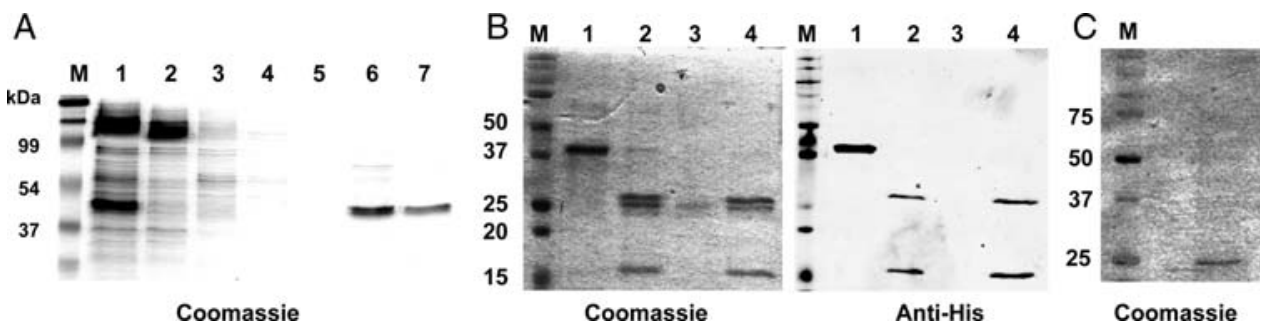

Fig. 4. Purification of TrxA-WbaP ${ }_{\text {CT. }}$ (A) Purification of $6 x$ His-TrxA-WbaP ${ }_{\mathrm{CT}}$ from C43(DE3) total membranes and analysis by $16 \%$ SDS-PAGE and Coomassie staining. Lane 1, DDM solubilization; lane 2, flow-through; lane 3, wash 1 (30 mM imidazole); lanes 4 and 5, wash 2 and 3 (60 mM imidazole); lane 6, elution

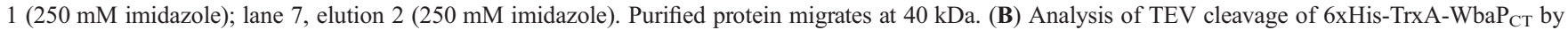
$16 \%$ SDS-PAGE followed by western blot with anti-HIS antibodies (right) and by Coomassie staining (left). Lane 1, purified 6xHis-TrxA-WbaP $\mathrm{CT}_{\mathrm{C}}$ migrates at $40 \mathrm{kDa}$; lane 2, 6xHis-TrxA-WbaP ${ }_{\mathrm{CT}}$ after TEV cleavage. Cleaved 6xHis-TrxA migrates at $17 \mathrm{kDa}$ and $\mathrm{WbaP}_{\mathrm{CT}}$ migrates at $25 \mathrm{kDa}$ and is not detected by western blot. The $6 x$ His-TEV protease migrates at $27 \mathrm{kDa}$. Lane 3, post-TEV-cleavage flow-through. Lane 4, elution with $500 \mathrm{mM}$ imidazole releases all bound protein. (C) 12\% SDS-PAGE and Coomassie staining of concentrated post-TEV-cleavage flow-through.
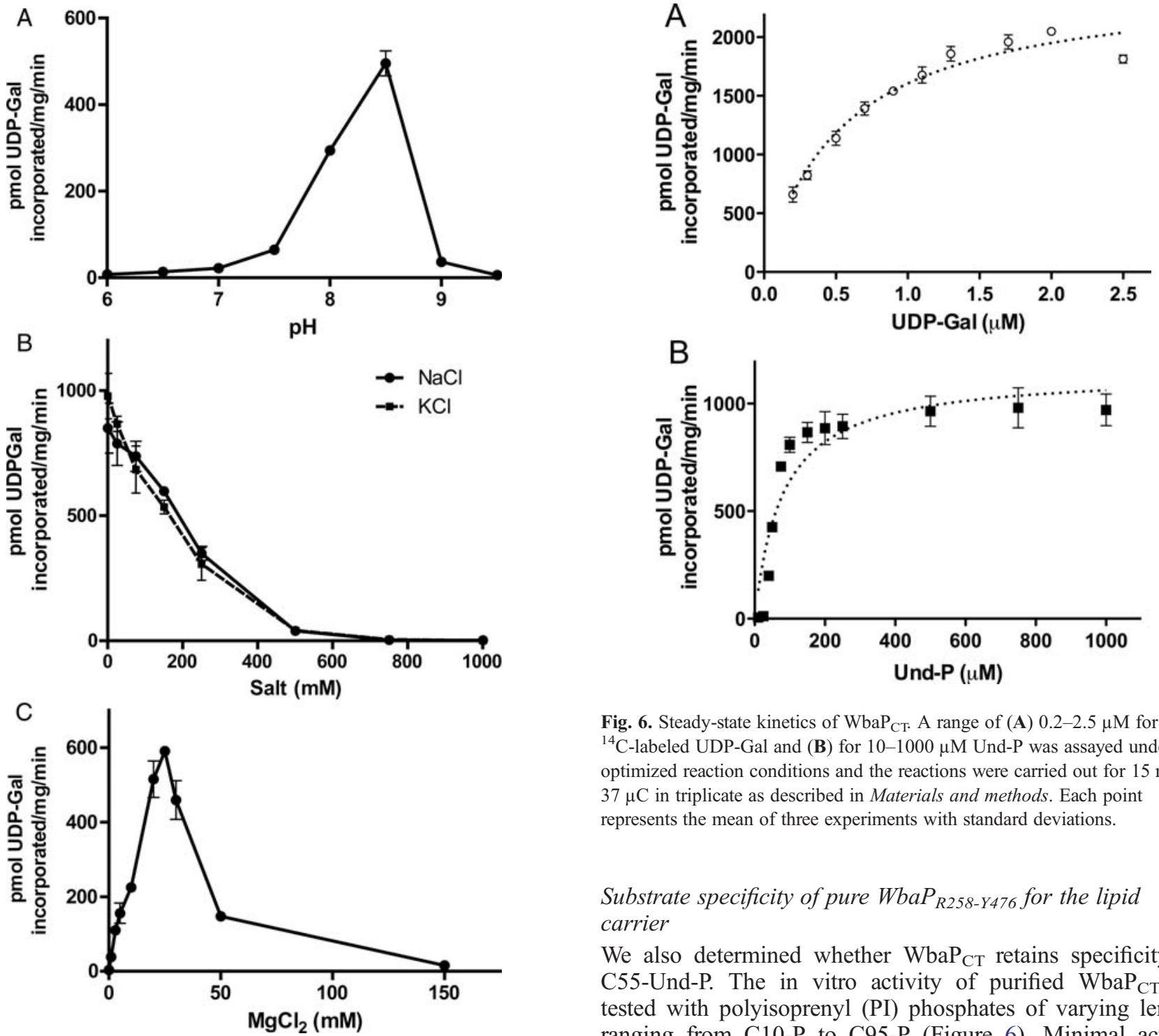

Fig. 6. Steady-state kinetics of $\mathrm{WbaP}_{\mathrm{CT}}$. A range of (A) $0.2-2.5 \mu \mathrm{M}$ for ${ }^{14} \mathrm{C}$-labeled UDP-Gal and (B) for 10-1000 $\mu \mathrm{M}$ Und-P was assayed under optimized reaction conditions and the reactions were carried out for $15 \mathrm{~min}$ at $37 \mu \mathrm{C}$ in triplicate as described in Materials and methods. Each point represents the mean of three experiments with standard deviations.

\section{Substrate specificity of pure WbaP $P_{R 258-Y 476}$ for the lipid carrier}

We also determined whether $\mathrm{WbaP}_{\mathrm{CT}}$ retains specificity for C55-Und-P. The in vitro activity of purified $\mathrm{WbaP}_{\mathrm{CT}}$ was tested with polyisoprenyl (PI) phosphates of varying lengths ranging from $\mathrm{C} 10-\mathrm{P}$ to C95-P (Figure 6). Minimal activity was detected with the shorter PIs C10-P, C15-P, C20-P and

Fig. 5. Biochemical properties of pure $\mathrm{WbaP}_{\mathrm{CT}}$. The effects of (A) $\mathrm{pH},(\mathbf{B})$ the salts $\mathrm{NaCl}$ and $\mathrm{KCl}$ and $(\mathbf{C}) \mathrm{MgCl}_{2}$ were investigated. Each data point represents the mean of three experiments with standard deviations. $\mathrm{C} 35-\mathrm{P}$ at $0.28,0.91,1$ and $1.8 \%$ of $\mathrm{C} 55-\mathrm{P}$ activity, respectively. A similar result was also obtained with the eukaryotic 


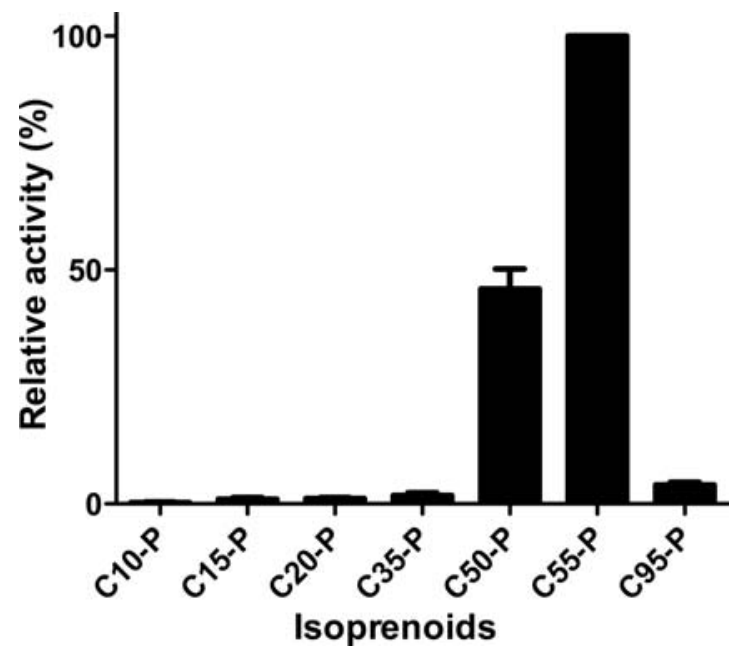

Fig. 7. Specificity of $\mathrm{WbaP}_{\mathrm{CT}}$ for the lipid carrier. A concentration of $100 \mu \mathrm{M}$ was used for each PI tested in optimized in vitro assay conditions as described in Materials and methods. Data represent the mean of three independent experiments with standard deviations.

lipid carrier, C95-P, at 4.02\% activity of C55-P (Figure 7). C50-P, however, resulted in $49.53 \%$ activity of C55-P. The synthetic $\mathrm{C} 55-\mathrm{P}$ and $\mathrm{C} 50-\mathrm{P}$ have three internal trans residues in their molecules, whereas the endogenous Und-P has two. Since the measurement of the enzymatic activity of purified WbaP $_{\mathrm{CT}}$ is related to the exogenous C55-P, we conclude that the differences in the number of trans residues are not relevant for substrate recognition. However, C35-P and C95-P have two internal trans units like authentic Und-P, and C95-P is hydrogenated at the $\mathrm{OH}$ of the terminal of the isoprene unit ( $\alpha$-isoprene). These results indicate that $\mathrm{WbaP}_{\mathrm{CT}}$ can recognize the length of the PI chain and the unsaturation of the $\alpha$-isoprene and therefore is highly specific for Und-P.

\section{Concluding remarks}

To our knowledge, in vitro studies on $\mathrm{WbaP}$ as well as other hexose-1-transferases, such as CpsE and WsaP, have relied on crude membrane preparations (Osborn et al. 1962; Cartee et al. 2005; Steiner et al. 2007; Saldías et al. 2008; Patel et al. 2010). Here, we have purified the $\mathrm{WbaP}_{\mathrm{CT}}$ domain, which has allowed us characterize the transferase reaction in vitro using chemically defined components. A striking observation in our study was the strong specificity of $\mathrm{WbaP}_{\mathrm{CT}}$ for Und-P. Kinetic analysis of purified PglC with PI phosphates varying in length, double-bond geometry and degree of saturation has also revealed a preference for the native substrate (Chen et al. 2007). An interaction of the enzyme with the Und-P (C55-P) acceptor presumably occurs in the inner membrane via regions of the protein within or at the boundaries of TM helices. In previous work, we showed the cytosolic tail of WbaP fused to TMI resulted in a protein without function, suggesting that the TMV is important for the catalytic activity of the enzyme (Saldías et al. 2008). A closer examination of the TMV helix, which is present in the purified $\mathrm{WbaP}_{\mathrm{CT}}$ protein, reveals the sequence LIIASPLMIYLWY. This sequence is strikingly similar to the 13 amino acids consensus sequence LL(F/I)IXFXXIPFXFY, which was described to be important for the recognition of PI phosphates (Albright et al. 1989; Zhou and Troy 2003). NMR and molecular modeling of peptides containing the consensus sequence suggest that one TM region would be sufficient to interact with Und-P (Albright et al. 1989; Zhou and Troy 2003, 2005). Structural studies of the $\mathrm{WbaP}_{\mathrm{CT}}$ domain, currently underway in our laboratory, will provide more detailed information on the mechanism of catalysis as well as the residues that make contact with substrate and cofactor molecules.

\section{Materials and methods}

\section{Bacterial strains and growth conditions}

Escherichia coli strains DH5 $\alpha$ (laboratory stock), BL21(DE3) (Invitrogen) and C43(DE3) (Invitrogen, Burlington, Ontario, Canada) were used for the overexpression of proteins. Salmonella enterica Typhimurium LT2 was used to prepare chromosomal DNA. Bacteria grew aerobically at $37^{\circ} \mathrm{C}$ in Luria-Bertani (LB) medium (Difco Laboratories, Sparks, $\mathrm{MD}$, USA) $(10 \mathrm{mg} / \mathrm{mL}$ tryptone, $5 \mathrm{mg} / \mathrm{mL}$ yeast extract, 5 $\mathrm{mg} / \mathrm{mL} \mathrm{NaCl}$ ). Media were supplemented with $100 \mu \mathrm{g} / \mathrm{mL}$ ampicillin, $30 \mu \mathrm{g} / \mathrm{mL}$ chloramphenicol or $40 \mu \mathrm{g} / \mathrm{mL}$ kanamycin as appropriate.

\section{Plasmid construction and sequencing}

Plasmid DNA was isolated using the Qiagen miniprep kit (Qiagen Inc., Mississauga, Ontario, Canada). Digestion with restriction enzymes, ligation with T4-ligase and transformation were carried out as described by Maniatis et al. (1982). DNA sequences were determined using an automated sequencer at the York University Core Molecular Biology and DNA Sequencing Facility, Toronto, Ontario, Canada. Plasmid pKP18 was constructed by polymerase chain reaction (PCR) amplification of a $624 \mathrm{bp}$ fragment using primers 2882 (5'-CTGGTCGACATTATTCAGTACTTCTCG-3') and 2907 (5'-CTAGTTAGGATCCAGGTCGTCCCGTTTTCTC-3') and LT2 DNA as template. This fragment was digested with SalI and BamHI and ligated into these sites in pET28a (Novagen, EMD Biosciences, Mississauga, Ontario, Canada). Plasmid pKP41 is described elsewhere (Patel et al. 2010).

\section{Chemicals}

All reagents unless otherwise specified were supplied by Sigma-Aldrich (St. Louis, MO, USA). ${ }^{14} \mathrm{C}$-labeled UDP-Gal (Specific activity of $300 \mathrm{mCi} / \mathrm{mmol}$ ) was purchased from American Radiolabeled Chemicals Inc. (St Louis, MO). Purified neryl monophosphate $\left(\mathrm{C}_{10} \mathrm{H}_{25} \mathrm{~N}_{2} \mathrm{O}_{4} \mathrm{P}\right)$, farnesyl monophosphate $\left(\mathrm{C}_{15} \mathrm{H}_{33} \mathrm{~N}_{2} \mathrm{O}_{4} \mathrm{P}\right)$, geranylgeranyl monophosphate $\left(\mathrm{C}_{20} \mathrm{H}_{41} \mathrm{~N}_{2} \mathrm{O}_{4} \mathrm{P}\right)$, heptaprenyl monophosphate $\left(\mathrm{C}_{35} \mathrm{H}_{65} \mathrm{~N}_{2} \mathrm{O}_{4} \mathrm{P}\right)$, decaprenyl monophosphate $\left(\mathrm{C}_{50} \mathrm{H}_{89} \mathrm{~N}_{2} \mathrm{O}_{4} \mathrm{P}\right)$, Und-P $\left(\mathrm{C}_{55} \mathrm{H}_{97} \mathrm{~N}_{2} \mathrm{O}_{4} \mathrm{P}\right)$ and dolichyl monophosphate $\left(\mathrm{C}_{95} \mathrm{H}_{163} \mathrm{~N}_{2} \mathrm{O}_{4} \mathrm{P}\right)$ were chemically phosphorylated using phosphoramidite chemistry (Branch et al. 1999; Ye et al. 2001). The purity of the PI phosphates was evaluated by thin layer chromatography and determined to be $>95 \%$ in all cases. To prepare the PI phosphates, prenols (C35, C50 and C55) were isolated from diverse plant sources (Wellburn and Hemming 1966), whereas dolichol (C95) was isolated from the 
mammalian liver and purified from the natural extracts by chromatographic methods (Chojnacki et al. 1975). Oligoprenols (C10, C15 and C20) were from Sigma-Aldrich.

\section{Membrane preparation and immunoblotting}

Bacteria grew overnight in $5 \mathrm{~mL}$ of LB. The culture was diluted to an initial $\mathrm{OD}_{600}$ of 0.2 and incubated at $37^{\circ} \mathrm{C}$ for $2 \mathrm{~h}$ until reaching an $\mathrm{OD}_{600}$ of 0.6. At this point, IPTG was added to a final concentration of $100-400 \mu \mathrm{M}$. Cells were incubated for $5 \mathrm{~h}$ at $30^{\circ} \mathrm{C}$. Cells were then harvested by centrifugation at $10,000 \times g$ for $10 \mathrm{~min}$ at $4^{\circ} \mathrm{C}$. The bacterial pellet was suspended in lysis buffer $[20 \mathrm{mM}$ Tris- $\mathrm{HCl}(\mathrm{pH} 8.5)+300 \mathrm{mM}$ $\mathrm{NaCl}$, unless otherwise specified] and protease inhibitor cocktail (Roche Diagnostics, Laval, Quebec, Canada) and the suspension lysed using a French Press cell (Thermo Scientific, Rockville, MD, USA). Cell debris were removed by centrifugation $\left(15,000 \times g\right.$ for $15 \mathrm{~min}$ at $\left.4^{\circ} \mathrm{C}\right)$, and the clear supernatant was centrifuged at $40,000 \times g$ for $30 \mathrm{~min}$ at $4^{\circ} \mathrm{C}$. The pellet, containing total membranes, was suspended in lysis buffer. The protein concentration was determined by the Bradford assay (Bio-Rad, Hercules, CA). Staining was performed with Coomassie brilliant blue R250 (Life Technologies Inc., Carlsbad, CA, USA). SDS-PAGE, protein transfers to nitrocellulose membranes and immunoblots were performed as described (Pérez et al. 2008). For detection of 6xHis proteins, membranes were incubated with a 1:10,000 dilution of anti-His IgG2a monoclonal antibodies (Amersham, Piscataway, NJ).

\section{Membrane protein solubilization}

For initial solubility detergent screening, total membranes from BL21(DE3) and C43(DE3) cells expressing pKP18 and pKP41 were solubilized in buffer $[20 \mathrm{mM}$ tris- $\mathrm{HCl}(\mathrm{pH} 8.5)$, $150 \mathrm{mM} \mathrm{NaCl}, 2 \mathrm{mM}$ 2-mercaptoethanol, $10 \%$ glycerol] containing $2.5 \%$ DDM, $7 \%$ Triton X-100 or $6 \%$ CHAPS in a final volume of $100 \mu \mathrm{L}$. The mixture was incubated at $4{ }^{\circ} \mathrm{C}$ for $2 \mathrm{~h}$ with rotation in a Barnstead Thermolyne LABQUAKE (Barnstead International, Dubuque, IA). After centrifugation at $40,000 \times g$ for $30 \mathrm{~min}$ at $4^{\circ} \mathrm{C}$, the supernatant, representing the soluble fraction, was collected. $10 \%$ of the soluble and pellet fractions were used for SDS-PAGE analysis. For screening to find an optimal detergent for enzymatic activity, the equivalent of $200 \mu \mathrm{g}$ of total membrane protein was solubilized in buffer [25 mM tris- $\mathrm{HCl}(\mathrm{pH} 8), 150 \mathrm{mM} \mathrm{NaCl}]$ and 0.5 or $1 \%$ of DDM, CHAPS, OG or Triton X-100 to a final volume of $200 \mu \mathrm{L}$ and the soluble fraction was recovered as described above. $2.5 \%$ of the insoluble and soluble fractions were used for SDS-PAGE analysis, and $50 \mu \mathrm{L}$ of the soluble fraction was used to determine in vitro enzymatic activity. For protein purification, total membranes were resuspended in buffer $[20 \mathrm{mM}$ tris- $\mathrm{HCl}(\mathrm{pH} 8.5), 300 \mathrm{mM} \mathrm{NaCl}$, $10 \mathrm{mM}$ 2-mercaptoethanol, $10 \%$ glycerol] with 1\% DDM and the soluble fractions was collected as described above.

\section{Purification of 6xHis-TrxA-WbaP ${ }_{C T}$ and cleavage by the} TEV protease

$\mathrm{Ni}^{2+}$-bound chelating Sepharose Fast Flow resin (GE Healthcare) equilibrated with wash buffer $[25 \mathrm{mM} \mathrm{NaPO} 4$ ( $\mathrm{pH}$ 7.5), $300 \mathrm{mM} \mathrm{NaCl}, 10 \mathrm{mM}$ 2-mercaptoethanol, $10 \mathrm{mM}$ imidazole, $10 \%$ glycerol and $0.03 \%$ DDM] was mixed with the cleared supernatant recovered after solubilization with $1 \%$ DDM. After $30 \mathrm{~min}$ at $4^{\circ} \mathrm{C}$ with rotation in a Barnstead Thermolyne LABQUAKE (Barnstead International, Dubuque, IA, USA), the resin was centrifuged at $3000 \times g$ and the flowthrough collected. The resin was washed with wash buffer containing 30 and $60 \mathrm{mM}$ imidazole and the protein was eluted with $250 \mathrm{mM}$. Elutions were combined and dialyzed overnight against $100 \times$ dialysis buffer $[25 \mathrm{mM} \mathrm{NaPO} 4(\mathrm{pH}$ 7.5), $150 \mathrm{mM} \mathrm{NaCl}, 10 \mathrm{mM}$ 2-mercaptoethanol, $10 \%$ glycerol and $0.03 \% \mathrm{DDM}]$. To remove the 6xHis-TrxA fusion, the dialyzed protein was concentrated $5 \times$ using a Vivaspin 20 centrifugal concentrator $(\mathrm{MWCO}=10,000)$ (Vivaproducts Inc., Littleton, MA). Five microliters of AcTEV protease (Invitrogen) was added to $500 \mu \mathrm{L}$ of protein and incubated at $4^{\circ} \mathrm{C}$ overnight. The next day the sample was added to $\mathrm{Ni}^{2}$ ${ }^{+}$-bound resin and the flow-through containing the cleaved protein was collected, concentrated and rinsed with buffer containing no salts. The cleaved protein was quantified using the bicinchoninic acid assay (Pierce, Thermo Scientific, Rockford, IL, USA).

\section{In vitro transferase assay}

To test the enzymatic activity of detergent solubilized samples, $50 \mu \mathrm{L}$ of solubilized protein was added to $50 \mathrm{mM}$ tris $-\mathrm{HCl}$ ( $\mathrm{pH}$ 8), $25 \mathrm{mM} \mathrm{MgCl}_{2}, 2 \mathrm{mM}$ 2-mercaptoethanol and $0.33 \mu \mathrm{M}$ ${ }^{14} \mathrm{C}$-labeled UDP-Gal to a final volume of $100 \mu \mathrm{L}$ and incubated for $30 \mathrm{~min}$ at $37^{\circ} \mathrm{C}$. For optimization of in vitro reaction conditions, effects of $\mathrm{pH}$, salt and magnesium ions were tested with 100,150 and $50 \mathrm{ng}$ of protein, respectively, and PIs were tested with $50 \mathrm{ng}$. Assays were performed with the addition of $100 \mu \mathrm{M}$ Und-P in a final volume of $50 \mu \mathrm{L}$. Steady-state kinetics were determined using optimized assay conditions $(\mathrm{pH}$ $8.5,25 \mathrm{mM} \mathrm{MgCl} 2,1 \%$ CHAPS). For UDP-Gal, $200 \mathrm{ng}$ of protein was tested in $100 \mu \mathrm{M}$ Und-P and in the range of $0.2-$ $125 \mu \mathrm{M}$ for ${ }^{14} \mathrm{C}$-labeled UDP-Gal. For Und-P, $100 \mathrm{ng}$ of protein was tested in $0.33 \mu \mathrm{M}{ }^{14} \mathrm{C}$-labeled UDP-Gal and in the range of $10-1000 \mu \mathrm{M}$ for Und-P. Reactions were incubated at $37^{\circ} \mathrm{C}$ for $15 \mathrm{~min}$. Extraction of the lipid fractions was adopted from Schäffer et al. (2002) with modifications. After incubation at $37^{\circ} \mathrm{C}$, the reactions were stopped with $200-400 \mu \mathrm{L}$ of chloroform-methanol (C:M 3:2). To extract the lipid phase, the mixture was shaken vigorously for $3 \mathrm{~min}$ and centrifuged for 2 $\min$ at $14,000 \times g$. The lower organic phase was collected and $55 \mu \mathrm{L}$ of $40 \mathrm{mM} \mathrm{MgCl} 2$ was added followed by 5 min of vigorous shaking. The mixture was centrifuged as before and the top phase was removed. The organic phase was washed twice with $200-400 \mu \mathrm{L}$ of pure solvent upper phase (C:M:W:1 M $\mathrm{MgCl}_{2}$ 18:294:293:1). For scintillation counting, the organic phase was added to $5 \mathrm{~mL}$ of scintillation fluid (Ecolume, MP Biomedical, Solon, $\mathrm{OH}$ ) and radioactivity was determined by a Beckman liquid scintillation counter (Beckman Coulter Canada, Inc., Mississauga, Ontario, Canada).

\section{Funding}

This work was supported by a grant from the Canadian Institutes of Health Research to M.A.V. K.B.P. was supported by an Ontario Graduate Scholarship in Science and 
Technology. M.A.V. holds a Canada Research Chair in Infection Diseases and Microbial Pathogenesis.

\section{Acknowledgements}

We thank C. Schäffer for help with the TLC method.

\section{Conflict of interest}

None declared.

\section{Abbreviations}

CHAPS, 3-[(3-cholamidopropyl)dimethylammonio]-1-propanesulfonate; DDM, $n$-dodecyl- $\beta$-D-maltoside; Gal, galactose; IPTG, isopropyl $\beta$-D-1-thiogalactopyranoside; LB, LuriaBertani; OG, octylglucoside; PCR, polymerase chain reaction; PHPT, polyisoprenyl-phosphate hexose-1-phosphate transferase; PI, polyisoprenyl; SDS-PAGE, sodium dodecyl sulfate-polyacrylamide gel electrophoresis; TEV, tobacco etch virus; TM, transmembrane; TrxA, thioredoxin; UDP, uridine monophosphate; Und-P, undecaprenyl monophosphate; $\mathrm{WbaP}_{\mathrm{CT}}$, WbaP C-terminal domain.

\section{References}

Albright CF, Orlean P, Robbins PW. 1989. A 13-amino acid peptide in three yeast glycosyltransferases may be involved in dolichol recognition. Proc Natl Acad Sci USA. 86:7366-7369.

Branch CL, Burton G, Moss SF. 1999. An expedient synthesis of allylic polyprenyl phosphates. Synth Commun. 29:2639-2644.

Cartee RT, Forsee WT, Bender MH, Ambrose KD, Yother J. 2005. CpsE from type 2 Streptococcus pneumoniae catalyzes the reversible addition of glucose-1-phosphate to a polyprenyl phosphate acceptor, initiating type 2 capsule repeat unit formation. J Bacteriol. 187:7425-7433.

Chamot-Rooke J, Rousseau B, Lanternier F, Mikaty G, Mairey E, Malosse C, Bouchoux G, Pelicic V, Camoin L, Nassif X, et al. 2007. Alternative Neisseria spp. type IV pilin glycosylation with a glyceramido acetamido trideoxyhexose residue. Proc Natl Acad Sci USA. 104:14783-14838.

Chen MM, Weerapana E, Ciepichal E, Stupak J, Reid CW, Swiezewska E, Imperiali B. 2007. Polyisoprenol specificity in the Campylobacter jejuni N-linked glycosylation pathway. Biochemistry. 46:14342-14348.

Chojnacki T, Jankowski W, Mankowski T, Sasak W. 1975. Preparative separation of naturally occurring mixtures of polyprenols on hydroxyalkoxypropylSephadex. Anal Biochem. 69:114-119.

Drummelsmith J, Whitfield C. 1999. Gene products required for surface expression of the capsular form of the group $1 \mathrm{~K}$ antigen in Escherichia coli (O9a:K30). Mol Microbiol. 31:1321-1332.

Geertsma ER, Groeneveld M, Slotboom DJ, Poolman B. 2008. Quality control of overexpressed membrane proteins. Proc Natl Acad Sci USA. 105:5722-5727.

Glover KJ, Weerapana E, Chen MM, Imperiali B. 2006. Direct biochemical evidence for the utilization of UDP-bacillosamine by PglC, an essential glycosyl-1-phosphate transferase in the Campylobacter jejuni $N$-linked glycosylation pathway. Biochemistry. 45:5343-5350.

Hartley MD, Morrison MJ, Aas FE, Borud B, Koomey M, Imperiali B. 2011. Biochemical characterization of the O-linked glycosylation pathway in Neisseria gonorrhoeae responsible for biosynthesis of protein glycans containing $N, N^{\prime}$-diacetylbacillosamine. Biochemistry. 50:4936-4948.

LaVallie ER, DiBlasio EA, Kovacic S, Grant KL, Schendel PF, McCoy JM. 1993. A thioredoxin gene fusion expression system that circumvents inclusion body formation in the E. coli cytoplasm. Bio/Technology. 11:187-193

Maniatis T, Fritsch EF, Sambrook J. 1982. Molecular Cloning: A Laboratory Manual. Cold Spring (NY): Cold Spring Harbor Laboratory Press.

Merino S, Jimenez N, Molero R, Bouamama L, Regue M, Tomas JM. 2011. A UDP-HexNAc:polyprenol-P GalNAc-1-P transferase (WecP) representing a new subgroup of the enzyme family. J Bacteriol. 193:1943-1952.

Miroux B, Walker JE. 1996. Over-production of proteins in Escherichia coli. Mutant hosts that allow synthesis of some membrane proteins and globular proteins at high levels. J Mol Biol. 260:289-298.

Osborn MJ, Rosen SM, Rothfield L, Horecker BL. 1962. Biosynthesis of bacterial lipopolysaccharide. I. Enzymatic incorporation of galactose in a mutant strain of Salmonella. Proc Natl Acad Sci USA. 48:1831-1838.

Patel KB, Furlong SE, Valvano MA. 2010. Functional analysis of the C-terminal domain of the WbaP protein that mediates initiation of $\mathrm{O}$ antigen synthesis in Salmonella enterica. Glycobiology. 20:1389-1401.

Pérez JM, McGarry MA, Marolda CL, Valvano MA. 2008. Functional analysis of the large periplasmic loop of the Escherichia coli K-12 WaaL O-antigen ligase. Mol Microbiol. 70:1424-1440.

Power PM, Roddam LF, Dieckelmann M, Srikhanta YN, Tan YC, Berrington AW, Jennings MP. 2000. Genetic characterization of pilin glycosylation in Neisseria meningitidis. Microbiology. 146:967-979.

Saldías MS, Patel K, Marolda CL, Bittner M, Contreras I, Valvano MA. 2008. Distinct functional domains of the Salmonella enterica WbaP transferase that is involved in the initiation reaction for synthesis of the $\mathrm{O}$ antigen subunit. Microbiology. 154:440-453.

Schäffer C, Wugeditsch T, Messner P, Whitfield C. 2002. Functional expression of enterobacterial O-polysaccharide biosynthesis enzymes in Bacillus subtilis. Appl Environ Microbiol. 68:4722-4730.

Steiner K, Novotny R, Patel K, Vinogradov E, Whitfield C, Valvano MA, Messner P, Schaffer C. 2007. Functional characterization of the initiation enzyme of S-layer glycoprotein glycan biosynthesis in Geobacillus stearothermophilus NRS 2004/3a. J Bacteriol. 189:2590-2598.

Stevenson G, Andrianopoulos K, Hobbs M, Reeves PR. 1996. Organization of the Escherichia coli K-12 gene cluster responsible for production of the extracellular polysaccharide colanic acid. J Bacteriol. 178:4885-4893.

Toh E, Kurtz HD, Jr, Brun YV. 2008. Characterization of the Caulobacter crescentus holdfast polysaccharide biosynthesis pathway reveals significant redundancy in the initiating glycosyltransferase and polymerase steps. $J$ Bacteriol. 190:7219-7231.

Valvano MA. 2003. Export of O-specific lipopolysaccharide. Front Biosci. 8: s452-s471.

Valvano MA, Furlong SE, Patel KA. 2011. Genetics, biosynthesis and assembly of $\mathrm{O}$ antigen. In: Knirel Y, Valvano MA, editors. Bacterial Lipopolysaccharides: Structure, Chemical Synthesis, Biogenesis and Interaction with Host Cells. Springer; New York.

Wang L, Liu D, Reeves PR. 1996. C-terminal half of Salmonella enterica WbaP (RfbP) is the galactosyl-1-phosphate transferase domain catalyzing the first step of O-antigen synthesis. J Bacteriol. 178:2598-2604.

Wang L, Reeves PR. 1994. Involvement of the galactosyl-1-phosphate transferase encoded by the Salmonella enterica $r f b P$ gene in O-antigen subunit processing. J Bacteriol. 176:4348-4356.

Wellburn AR, Hemming FW. 1966. The occurrence and seasonal distribution of higher isoprenoid alcohols in the plant kingdom. Phytochemistry. 5:969-975.

Ye XY, Lo MC, Brunner L, Walker D, Kahne D, Walker S. 2001. Better substrates for bacterial transglycosylases. $J$ Am Chem Soc. 123: $3155-3156$.

Zhou GP, Troy FA, 2nd. 2003. Characterization by NMR and molecular modeling of the binding of polyisoprenols and polyisoprenyl recognition sequence peptides: 3D structure of the complexes reveals sites of specific interactions. Glycobiology. 13:51-71.

Zhou GP, Troy FA. 2005. NMR study of the preferred membrane orientation of polyisoprenols (dolichol) and the impact of their complex with polyisoprenyl recognition sequence peptides on membrane structure. Glycobiology. 15:347-359. 